\title{
The origin of the chemical profiles of fungal symbionts and their significance for nestmate recognition in Acromyrmex leaf-cutting ants
}

Richard, Freddie-Jeanne; Poulsen, Michael; Hefetz, Abraham; Errard, Christine; Nash, David; Boomsma, Jacobus

Published in:

Behavioral Ecology and Sociobiology

DOI:

10.1007/s00265-007-0395-1

Publication date:

2007

Document version

Publisher's PDF, also known as Version of record

Citation for published version $(A P A)$ :

Richard, F-J., Poulsen, M., Hefetz, A., Errard, C., Nash, D., \& Boomsma, J. (2007). The origin of the chemical profiles of fungal symbionts and their significance for nestmate recognition in Acromyrmex leaf-cutting ants. Behavioral Ecology and Sociobiology, 61(11), 1637-1649. https://doi.org/10.1007/s00265-007-0395-1 


\title{
The origin of the chemical profiles of fungal symbionts and their significance for nestmate recognition in Acromyrmex leaf-cutting ants
}

\author{
Freddie-Jeanne Richard • Michael Poulsen • \\ Abraham Hefetz • Christine Errard • David R. Nash • \\ Jacobus J. Boomsma
}

Received: 13 October 2006 /Revised: 14 March 2007 / Accepted: 9 April 2007 /Published online: 10 May 2007

(C) Springer-Verlag 2007

\begin{abstract}
Cuticular hydrocarbon profiles are essential for nestmate recognition in insect societies, and quantitative variation in these recognition cues is both environmentally and genetically determined. Environmental cues are normally derived from food or nest material, but an exceptional situation may exist in the fungus-growing ants where the symbiotic fungus garden may be an independent source of recognition compounds. To investigate this hypothesis, we quantified the chemical profiles of the fungal symbionts of 18 sympatric colonies of Acromyrmex echinatior and Acromyrmex octospinosus and evaluated the quantitative variation of the 47 compounds in a multivariate analysis. Colony-specific chemical profiles of fungal symbionts were highly distinct and significantly different between the two ant species. We also estimated the relative genetic distances between the fungal symbionts using amplified fragment
\end{abstract}

Communicated by K. Ross

Freddie-Jeanne Richard and Michael Poulsen contributed equally to this work.

F.-J. Richard · C. Errard

Institut de Recherche sur la Biologie de l'Insecte,

CNRS UMR 6035, Faculté des Sciences, Parc de Grandmont,

37200 Tours, France

F.-J. Richard

e-mail: fjrichard@ncsu.edu

C. Errard

e-mail: Errard@univ-tours.fr

M. Poulsen · D. R. Nash • J. J. Boomsma

Department of Population Biology, Institute of Biology,

University of Copenhagen,

2100 Copenhagen, Denmark

D. R. Nash

e-mail: DRNash@bi.ku.dk length polymorphism (AFLP) and correlated these with the overall (Mahalanobis) chemical distances between the colony-specific profiles. Despite the standardized laboratory conditions, the correlations were generally weak, but a statistically significant portion of the total variation in chemical profiles could be explained by genetic differences between the fungal symbionts. However, there was no significant effect of ant species in partial analyses because genetic differences between symbionts tend to coincide with being reared by different ant species. However, compound groups differed significantly with amides, aldehydes, and methyl esters contributing to the correlations, but acetates, alkanes, and formates being unrelated to genetic variation among symbionts. We show experimentally that workers that are previously exposed to and fed with the fungal symbiont of another colony are met with 
less aggression when they are later introduced into that colony. It appears, therefore, that fungus gardens are an independent and significant source of chemical compounds, potentially contributing a richer and more abundant blend of recognition cues to the colony "gestalt" than the innate chemical profile of the ants alone.

Keywords Fungus-growing ants $\cdot$ Basidiomycete . Symbiosis $\cdot$ Mutualism $\cdot$ Hydrocarbon profile .

Gas chromatography $\cdot$ AFLP

\section{Introduction}

The eusocial insects (ants, wasps, bees, and termites) discriminate nestmates from alien individuals using complex, colony-specific chemical mixtures that are partly determined genetically (e.g., Vander Meer and Morel 1998), but also include substantial environmental components (Richard et al. 2004, and references therein). Hydrocarbons are thought to be an important component of such nestmate recognition labels (e.g., Singer 1998; Breed 1998; Vander Meer and Morel 1998; Lenoir et al. 1999). Each member of an insect society may have an individual hydrocarbon profile, but discrimination between nestmates and nonnestmates appears to be based on a composite colony-specific "gestalt" profile common to all colony members (Crozier and Dix 1979; Fletcher and Michener 1987). This colony "gestalt" is maintained by the continuous exchange of recognition cues via trophallaxis and allogrooming (Soroker et al. 1994), and can therefore track seasonal variation in diet (Nielsen et al. 1999; Richard et al. 2004; Silverman and Liang 2001) and nesting substrate (Heinze et al. 1996).

Atta and Acromyrmex leaf-cutting ants (Formicidae: Attini) cultivate mutualistic fungi of the family Lepiotaceae (Agaricales: Basidiomycota) (Weber 1966; Chapela et al. 1994) in underground nest chambers (Belt 1874; Möller 1893). These ectosymbionts serve as the exclusive food for the ant brood and are a major part of the worker diet (Cherrett et al. 1989; Littledyke and Cherrett 1976; Quinlan and Cherrett 1979; Murakami and Higashi 1997; Schneider 2000). The ants maintain their fungal symbionts by providing suitable plant-fragment substrate, by manuring fungus gardens with fecal droplets, and by protecting their cultivars from contamination with bacteria, fungal competitors, and pathogens (Bass and Cherrett 1994; North et al. 1997; Currie et al. 1999, 2003, 2006; Currie and Stuart 2001; Bot et al. 2002).

In behavioral tests, both Acromyrmex leaf-cutting ant workers (Bot et al. 2001; Viana et al. 2001) and ants in the "lower" attine genus Cyphomyrmex (Mueller et al. 2004; Mehdiabadi et al. 2006) discriminate between their resident fungal cultivar and fragments of fungi from other sympatric colonies of the same or closely related species, possibly because the fungi carry specific chemical signatures (Viana et al. 2001). The domesticated fungi themselves have also recently been shown to actively reject genetically different fungus clones from other colonies of the same population (Poulsen and Boomsma 2005). Moreover, the fecal droplets that the ants use to manure their fungus garden carry an imprint of the resident fungus so that they are incompatible with symbionts from other colonies, unless these are genetically identical (Poulsen and Boomsma 2005).

The discovery of these multiple layers of possible incompatibility between the farming ants and their fungal symbionts is so recent that the proximate chemical and enzymatic mechanisms behind these interactions are virtually unknown. In the present study, we attempt to open one of these black boxes by analyzing the chemical profiles of fungus gardens cultivated by two sympatric Panamanian Acromyrmex species. We do this by comparing the quantitative differences in these profiles with amplified fragment length polymorphism (AFLP)-based genetic distances between these fungal symbionts and by experimentally evaluating the effect of previous exposure to nonnestmate fungus for later discrimination between nestmates and nonnestmates.

\section{Materials and methods}

Fungus material

A total of 42 fungus gardens were used, originating from 22 colonies of Acromyrmex echinatior (Ae colony numbers 33, $47,48,109,112,124,128,131,132,144,145,150,152$, 153,162, 168, 190, 191, 197, 208, 209, and 210) and 20 colonies of Acromyrmex octospinosus (Ao colony numbers $21,35,67,103,107,114,117,119,163,165,173,169$, 181, 198, 201, 203, 205, FS2, GIP, and AH5). All colonies were collected between 1994 and 2002 in Gamboa, Panama, except for AH5 (from Ancon Hill at a distance of approximately $25 \mathrm{~km}$ ) and FS2 (from Fort Sherman at a distance of approximately $35 \mathrm{~km}$ ). At the time of sampling for the present study, all colonies were maintained in laboratory nest boxes in a climate room at the University of Copenhagen under standardized conditions of approximately $70 \%$ relative humidity, temperature of $25^{\circ} \mathrm{C}$, and were fed ad libitum with a standard diet of bramble (Rubus) leaves and rice.

Chemical analysis of fungus clones

Nine fungus gardens for each of the two ant species were used for the chemical analyses (Ae 33, 48, 109, 145, 168, 197, 208, 209, and 210 and Ao 35, 163, 169, 181, 198, 201, 
205, GIP, and AH5) because they had fungus garden volumes of at least half a liter. To minimize any contaminating effects of leaf fragments, samples were taken from the mature parts of fungus gardens, well below the upper layer containing freshly incorporated or undigested leaf fragments. All ant brood and workers were removed from the fungus fragments before chemical extraction, which was carried out using $200 \mathrm{mg}$ of fungus material from each of 5 replicates per fungus garden. Such multiple samples from the same fungus garden always yield mycelia from the same symbiont clone (Poulsen and Boomsma 2005). Extractions were carried out by immersing fungus material in $3 \mathrm{ml}$ pentane for $10 \mathrm{~min}$ after which the extracts were stored at $-20^{\circ} \mathrm{C}$ until chemical analysis. Before analysis, the pentane was allowed to evaporate and the dried extracts were redissolved in $50 \mu \mathrm{l}$ pentane containing $10 \mu \mathrm{g} / \mu \mathrm{l}$ eicosane $\left(n-\mathrm{C}_{20}\right)$ as an internal standard. Two microliters of this mixture were injected into a gas chromatograph (Perkin Elmer Autosystem XL, FID). Compound separation was achieved using a BP1 fusedsilica capillary column (SGE; $0.5 \mu ; 25 \mathrm{~m} \times 0.32 \mathrm{~mm}$ ) that was held at an initial temperature of $150^{\circ} \mathrm{C}$ for $2 \mathrm{~min}$, based on preliminary data indicating this being an optimal starting point for fungus profile acquisition (F.-J. Richard, unpublished data), and then programmed for a gradual temperature rise of $5^{\circ} \mathrm{C} / \mathrm{min}$ until the maximum temperature of $300^{\circ} \mathrm{C}$ was reached and maintained for $10 \mathrm{~min}$. We used mass spectrometry (bench top Perkin Elmer Turbomass system using EI mode at $70 \mathrm{eV}$ ) for compound identification, and compared mass spectra with NIST/EPA/NIH libraries before quantification and characterization of chemical profiles by valley-to-valley peak integration (see Table 1). To obtain normalized data for subsequent analysis, peak areas were log-ratio-transformed (i.e., each peak area was replaced by the log of the ratio of the area of that peak to the geometric mean peak area of the other compounds; cf. Aitchison 2003; Nielsen et al. 1999) to give an unbounded measure of the relative abundances of the individual compounds compared with all other compounds (the analysis of Fig. 1) or others belonging to the same compound group (alkanes, aldehydes, amides, formates, methyl esters or acetates: the analyses of Tables 2 and 3; Fig. 3). For the latter analyses, all groups with at least three different compounds were included, except for acids $(n=5)$ for which the peak area determinations were not accurate enough to justify inclusion at this detailed level.

Genetic analysis of fungus clones

\section{Isolating and cultivating the mutualistic fungus}

Fungus clones were isolated as pure cultures in vitro by inoculating 1-2 $\mathrm{mm}^{3}$ of mycelium from the fungus garden on a medium of potato dextrose agar (PDA) in Petri dishes (concentration $39.7 \mathrm{~g}$ PDA/l; Sigma-Aldrich) with a sterilized needle. Isolates were kept at $25^{\circ} \mathrm{C}$, and any contaminated plates were discarded. Liquid medium (potato dextrose broth [PDB] at a concentration of $24 \mathrm{~g} \mathrm{PDB} / 1$; ICN Biomedicals) was prepared and poured into $50 \mathrm{ml}$ vials that could be sealed with sterilized aluminum foil. Fungal tufts from the PDA plates were transferred to these vials and were left for approximately 3 weeks before the material was taken out for DNA analysis.

\section{DNA isolation and AFLP}

Isolations were carried out using fungal hyphae from liquid culture. To avoid any impact of the medium present, fungus material was spun down for $5 \mathrm{~min}$ at $6000 \mathrm{rpm}$ and the supernatant (i.e., any medium present) was removed. The DNeasy Plant Mini Kit (Qiagen, 40724, Hilden, Germany) was used for DNA isolation. AFLP analysis was performed using the protocol available at http://www.biology. leidenuniv.nl $/ \mathrm{ibl} / \mathrm{mollab} /$ and as described by Vos et al. (1995) (see also Bot et al. 2001; Poulsen and Boomsma 2005). After amplification reactions, products were run on an ABI Prism ${ }^{\mathrm{TM}}$, after which band patterns were analyzed using GeneScan Analysis ${ }^{\mathrm{TM}}$ 2.0.2 (Perkin Elmer). A total of 85 bands of different lengths were obtained. These were treated as binary characters, i.e., scored as present or absent in all 42 fungus clones, and were inserted into a data matrix. All peaks above intensity 30 were scored because this threshold guaranteed $100 \%$ repeatability in subsequent AFLP runs (Poulsen and Boomsma 2005; M. Poulsen, unpublished data). A midpoint-rooted phylogram was estimated using PAUP*4.0b10 (Swofford 2002), inferring a phylogenetic tree from a heuristic search with random input order and TBR branch swapping. Node support was assessed by 1,000 bootstrap pseudoreplicates under neighborjoining conditions (Hall 2001), and the relative genetic distance between pairs of clones was calculated as the proportion of nonhomologous bands between pairs of clones (PAUP*4.0b10; Swofford 2002).

The role of fungus chemicals in nonnestmate recognition

To evaluate whether fungus chemical profiles affect aggression toward nonnestmates, we performed intraspecific and interspecific nestmate recognition experiments between ants originating from four different mature colonies before and after ant-cultivar transplants. We used two A. echinatior (Ae 288 and CC031209-02) and two $A$. octospinosus (CC030403-09 and CC031210-22) colonies, which were all of similar size (1.5-2 1 of fungus garden material) and maintained at the UW-Madison under identical climatic and feeding conditions. While the genetic 
Table 1 The 47 chemical compounds that were extracted from fungus gardens cultivated by A. echinatior and A. octospinosus (identical for the 2 ant species)

\begin{tabular}{|c|c|c|}
\hline$N$ & Peak Identity & Characteristic ions \\
\hline 1 & Pentadecanal (Ald) & $82^{\mathrm{b}} ; 182 ; 208^{\mathrm{m}-18}$ \\
\hline 2 & Heptadecane (Alk) & $57^{\mathrm{b}} ; 71 ; 85 ; 99 ; 240^{\mathrm{mi}}$ \\
\hline 3 & Hexadecanal (Ald) & $82^{\mathrm{b}} ; 196 ; 222^{\mathrm{m}-18}$ \\
\hline 4 & Octadecane (Alk) & $57 ; 71 ; 85 ; 99 ; 254^{\mathrm{mi}}$ \\
\hline 5 & 8-Methyloctadecane (Alk) & $57^{\mathrm{b}} ; 71 ; 85 ; 99 ; 126 ; 168 ; 254^{\mathrm{mi}}$ \\
\hline 6 & 2-Octadecanone (Ket) & $58 \mathrm{~b} ; 109 ; 210 ; 250 ; 268^{\mathrm{mi}}$ \\
\hline 7 & Pentadecanoic acid (Aci) & $60 ; 73^{\mathrm{b}} ; 129 ; 199 ; 242^{\mathrm{mi}}$ \\
\hline 8 & Heptadecanal (Ald) & $82^{\mathrm{b}} ; 109 / 110 ; 210 ; 236^{\mathrm{m}-18}$ \\
\hline 9 & Palmitic acid (Aci) & $60 ; 73^{\mathrm{b}} ; 129 ; 213256^{\mathrm{mi}}$ \\
\hline $\mathrm{S}$ & Eicosane $^{\mathrm{a}}$ & $57^{\mathrm{b}} ; 71 ; 85 ; 99 ; 282^{\mathrm{mi}-}$ \\
\hline 10 & Linoleic acid (Aci) & $60 ; 67^{\mathrm{b}} ; 95 ; 109 ; 280^{\mathrm{mi}}$ \\
\hline 11 & Oleic acid (Aci) & $55^{\mathrm{b}} ; 60 ; 69 ; 83 ; 97 ; 220 ; 264 ; 282^{\mathrm{m}}$ \\
\hline 12 & Stearic acid (Aci) & $60 ; 73^{\mathrm{b}} ; 129 ; 185 ; 241 ; 284^{\mathrm{mi}}$ \\
\hline 13 & Docosane (Alk) & $57^{\mathrm{b}} ; 71 ; 85 ; 99 ; 310^{\mathrm{mi}}$ \\
\hline 14 & Eicosanal (Ald) & $82^{\mathrm{b}} ; 96 ; 109 / 110 ; 278^{\mathrm{m}-18}$ \\
\hline 15 & Tricosane (Alk) & $57^{\mathrm{b}} ; 71 ; 85 ; 99 ; 324^{\mathrm{mi}}$ \\
\hline 16 & Heneicosanal (Ald) & $82^{\mathrm{b}} ; 96 ; 109 / 110 ; 264 ; 292^{\mathrm{m}-18}$ \\
\hline 17 & Oleyl amide (Ami) & $59^{\mathrm{b}} ; 72 ; 281^{\mathrm{mi}}$ \\
\hline 18 & Tetracosane (Alk) & $57^{\mathrm{b}} ; 71 ; 85 ; 99 ; 338^{\mathrm{mi}}$ \\
\hline 19 & Docosanal (Ald) & $82^{\mathrm{b}} ; 96 ; 109 / 110 ; 278 ; 306^{\mathrm{m}-18}$ \\
\hline 20 & Docosyl formate (For) & $57 ; 69 ; 83^{\mathrm{b}} ; 280 ; 308^{\mathrm{m}-46}$ \\
\hline 21 & Pentacosane (Alk) & $57^{\mathrm{b}} ; 71 ; 85 ; 99 ; 352^{\mathrm{mi}}$ \\
\hline 22 & Tricosanal (Ald) & $82^{\mathrm{b}} ; 96 ; 109 / 110 ; 292 ; 320^{\mathrm{m}-18}$ \\
\hline 23 & Eicosenyl amide (Ami) & $59^{\mathrm{b}} ; 72 ; 309^{\mathrm{mi}}$ \\
\hline 24 & Hexacosane (Alk) & $57^{\mathrm{b}} ; 71 ; 85 ; 99 ; 366^{\mathrm{mi}}$ \\
\hline 25 & Tetracosanal (Ald) & $82^{\mathrm{b}} ; 96 ; 109 / 110 ; 306 ; 334^{\mathrm{m}-18}$ \\
\hline 26 & Heptacosadiene (Alke) & $67^{\mathrm{b}} ; 82 ; 96 ; 110 ; 376^{\mathrm{mi}}$ \\
\hline 27 & Tetracosyl formate (For) & $57 ; 69 ; 83^{\mathrm{b}} ; 308 ; 336^{\mathrm{m}-46}$ \\
\hline 28 & Heptacosane (Alk) & $57^{\mathrm{b}} ; 71 ; 85 ; 99 ; 378^{\mathrm{mi}}$ \\
\hline 29 & Pentacosanal (Ald) & $82^{\mathrm{b}} ; 96 ; 109 / 110 ; 348^{\mathrm{m}-18}$ \\
\hline 30 & Docosenyl amide (Ami) & $59^{\mathrm{b}} ; 72 ; 337^{\mathrm{mi}}$ \\
\hline 31 & Octacosene (Alke) & $55^{\mathrm{b}} ; 69 ; 83 ; 97 ; 392$ \\
\hline 32 & Octacosane (Alk) & $57^{\mathrm{b}} ; 71 ; 85 ; 99 ; 394^{\mathrm{mi}}$ \\
\hline 33 & Hexacosanal (Ald) & $82^{\mathrm{b}} ; 96 ; 109 / 110 ; 362^{\mathrm{m}-18}$ \\
\hline 34 & Hexacosyl formate (For) & $57 ; 69 ; 83^{\mathrm{b}} ; 336 ; 364^{\mathrm{m}-46}$ \\
\hline 35 & Nonacosane (Alk) & $57^{\mathrm{b}} ; 71 ; 85 ; 99 ; 408^{\mathrm{mi}}$ \\
\hline 36 & Methyl hexacosanoate (Met) & $74^{\mathrm{b}} ; 87 ; 143 ; 366 ; 410^{\mathrm{mi}}$ \\
\hline 37 & Hexacosyl acetate (Ace) & $57^{\mathrm{b}} ; 61 ; 83 ; 97 ; 336 ; 364^{\mathrm{m}-60}$ \\
\hline 38 & Octacosanal (Ald) & $82^{\mathrm{b}} ; 96 ; 109 / 110 ; 390^{\mathrm{m}-18}$ \\
\hline 39 & Octacosyl formate (For) & $57 ; 69 ; 83^{\mathrm{b}} ; 364 ; 392^{\mathrm{m}-46}$ \\
\hline 40 & Hentriacontane (Alk) & $57^{\mathrm{b}} ; 71 ; 85 ; 99 ; 436^{\mathrm{mi}}$ \\
\hline 41 & Methyl octacosanoate (Met) & $74^{\mathrm{b}} ; 87 ; 143 ; 394 ; 438^{\mathrm{mi}}$ \\
\hline 42 & Octacosyl acetate (Ace) & $57^{\mathrm{b}} ; 61 ; 83 ; 97 ; 364 ; 392^{\mathrm{m}-60}$ \\
\hline 43 & Triacontanal (Ald) & $82^{\mathrm{b}} ; 96 ; 109 / 110 ; 418^{\mathrm{m}-18}$ \\
\hline 44 & Triacontyl formate (For) & $57 ; 69 ; 83^{\mathrm{b}} ; 392 ; 420^{\mathrm{m}-46}$ \\
\hline 45 & Tritriacontane (Alk) & $57^{\mathrm{b}} ; 71 ; 85 ; 99 ; 464^{\mathrm{mi}}$ \\
\hline 46 & Methyl triacontanoate (Met) & $74^{\mathrm{b}} ; 87 ; 143 ; 422 ; 466^{\mathrm{mi}}$ \\
\hline 47 & Triacontyl acetate (Ace) & $57^{\mathrm{b}} ; 61 ; 83 ; 97 ; 392 ; 420^{\mathrm{m}-60}$ \\
\hline
\end{tabular}

$N$ is the position of each compound on the chromatogram (from left to right). Chemical identities are based on ion characteristics with ions marked as "b" designating the base peak (i.e., the most abundant fragment), ions marked as "mi" designating the molecular ion (molecular weight), and ions marked with " $\mathrm{m}$-\#" designating the heaviest ion detected with the specified number indicating the complementary ion to the molecular weight. Peak 27 was too small to be integrated and was not used in the subsequent analyses. The classes of compounds distinguished in Table 2 are given in parenthesis: Alkanes (Alk), Alkenes (Alke), Aldehydes (Ald), Amides (Ami), Formates (For), Methyl esters (Met), Ketones (Ket), Acetates (Ace), and Acids (Aci). Note that only those with more than three compounds per group (acids excluded) were used for the analyses in Table 2 (see text for details). ${ }^{a}$ Eicosane (peak $\mathrm{S}$ in Fig. 1a) was the internal standard. 


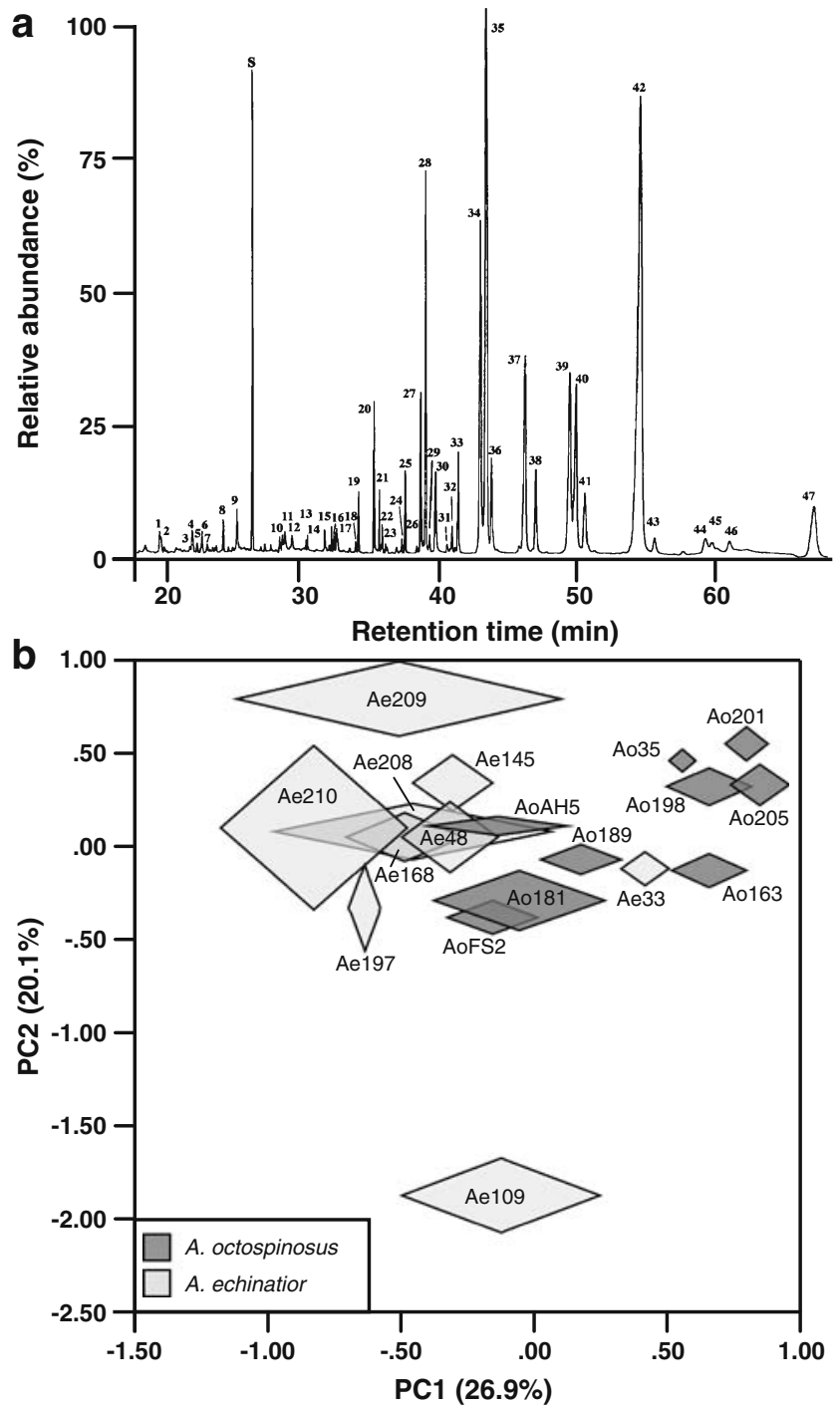

Fig. 1 a A representative example of a gas chromatogram of a fungal symbiont of $A$. echinatior (colony Ae 48). The peaks that were identified are listed in Table 1. b Principal components graph showing the chemical similarity between the fungus gardens of 9 colonies of $A$. octospinosus (darker diamonds) and 9 colonies of A. echinatior (lighter diamonds) based on 47 compounds. Each diamond represents one colony with the mean of the five replicates extracted from the fungus clone at its center. The width and height of each diamond represent \pm 1 standard error of the mean for PC1 and PC2, respectively

profiles of the fungus clones reared by these colonies was unknown, the presence of ant-fungus incompatibility when workers were presented with fungus from either one of their nonnative colonies (MP, unpublished data) suggests that each of the four colonies indeed reared a genetically distinct fungus clones (cf. Bot et al. 2001). First, typical nonnestmate aggression levels were determined by marking 40 major workers with nail polish and adding 10 of these workers to each of the 4 colonies. The 10 workers returned to their own colony thus served as controls for potential handling and nail polish marking effects, whereas the $3 \times 10$ workers introduced in alien colonies served as replicate treatment groups. The refuse piles of all 4 colonies were examined for dead introduced workers 24 hours after introduction, and aggression level was estimated as the proportion of marked workers killed after introduction. In a second experiment, we investigated whether priming the ants with exposure to and feeding on the fungus of the receiving colony would alter the baseline levels of aggression established in the first experiment. We therefore set up 10 other workers from the same 4 colonies in subcolonies with fungus from either their own or 1 of the other 3 colonies, using standard ant-cultivar transplant techniques (Bot et al. 2001; Poulsen and Boomsma 2005). Each subcolony was provided with approximately $5.0 \mathrm{~g}$ fungus material without minor workers or brood. These transplanted fungal fragments were often completely destroyed by the ants during the first days, as expected from incompatibility reactions between unrelated symbionts, whereas the controls remained unaffected (Poulsen and Boomsma 2005). Subcolonies were therefore provided with fresh fungus material from the source colonies every second day, while remnants of the previous fungus were removed (cf. Bot et al. 2001). Fourteen days after the transplants were initiated, all subcolonies had accepted their novel symbiont and workers were maintaining the nonresident fungus, as expected from previous work (Bot et al. 2001; Poulsen and Boomsma 2005). At this point in time, we repeated the (non)nestmate aggression tests by introducing the marked workers from the subcolonies into the nests from which their transplanted fungus had originated and counted the number of introduced workers killed by resident workers $24 \mathrm{~h}$ after their introduction.

Statistical analysis

To test for differences in chemical profiles between different fungus gardens, a principal components analysis was first carried out on the log-ratio-transformed peak areas of 37 of the 47 identified compounds that were reliably and quantifiable (i.e., peaks that were consistently below $1 \%$ of the total and acids were omitted), based on their covariances. The first two principal components were then used in separate nested ANOVAs to assess the chemical distinctness of fungus gardens from the different colonies within each ant species. This analysis was performed using JMP 5.1 (SAS Institute). For additional analyses, the chemical distance between each pair of fungus gardens was estimated as the Mahalanobis distances between centroids for the pairs of clones, obtained from a discriminant analysis of the log-ratio-transformed peak areas for each chemical group (S-Plus v. 6.1, Insightful). These distances were correlated with the AFLP-generated genetic distances using Mantel tests of matrix correlation (Mantel 1967), which were 
Table 2 The results of Mantel tests of matrix correlation between relative chemical and relative genetic distances across the 18 fungal clones investigated

\begin{tabular}{llllllll}
\hline & $\begin{array}{l}\text { All identified compounds } \\
(n=47)\end{array}$ & $\begin{array}{l}\text { Alkanes } \\
(n=13)\end{array}$ & $\begin{array}{l}\text { Aldehydes } \\
(n=12)\end{array}$ & $\begin{array}{l}\text { Amides } \\
(n=3)\end{array}$ & $\begin{array}{l}\text { Formates } \\
(n=5)\end{array}$ & $\begin{array}{l}\text { Methyl esters } \\
(n=3)\end{array}$ \\
\hline Both species & -0.067 & 0.027 & 0.023 & $\mathbf{0 . 1 4}$ & 0.063 & 0.068 \\
& $(0.71)$ & $(0.37)$ & $(0.39)$ & $(\mathbf{0 . 0 9 3})$ & $(0.27)$ & $\begin{array}{l}\text { Acetates } \\
(n=3)\end{array}$ \\
A.octospinosus & 0.22 & 0.21 & $\mathbf{0 . 2 2}$ & 0.16 & 0.15 & $\mathbf{0 . 2 4}$ & $(0.60)$ \\
& $(0.12)$ & $(0.12)$ & $(\mathbf{0 . 0 9 6}$ & $(0.18)$ & $(0.21)$ & $\mathbf{( 0 . 0 9 6 )}$ & $(0.11$ \\
A. echinatior & 0.0066 & 0.11 & 0.11 & $\mathbf{0 . 2 5}$ & 0.17 & $\mathbf{0 . 3 1}$ \\
& $(0.40)$ & $(0.22)$ & $(0.22)$ & $\mathbf{( 0 . 0 7 8 )}$ & $(0.14)$ & $(\mathbf{0 . 0 3 2})$ & $(0.17)$ \\
\hline
\end{tabular}

$r$ values obtained are given with one-tailed $P$ values in parenthesis. All positive associations with $P<0.1$ are marked in bold.

performed using either of the computer programs Arlequin 2.1 (Schneider et al. 2000) or F-stat (Goudet 1995) with significance assessed using 1,000 permutations. Mantel tests were also carried out to check whether there was any correlation between the geographic distance, obtained from digitization of maps of the sampling area in Gamboa using the computer program MacGPS Pro 5.0.0 (James Associates, Nederland, CO 80466, USA), and the chemical or genetic similarity of the fungus clones reared by the different ant colonies. Significances of correlation analyses are onetailed because only positive correlations were expected. Correlations between genetic and geographic distances were carried out for all 42 colonies from which AFLP's were obtained, for the subset of 18 colonies where chemical distances were also available, and as a partial Mantel test using an independent, binary matrix encoding whether chemistry was known or not, to control for the difference in genetic distances (higher in the substantially larger group of colonies from which chemical distances were not available).

Although Mantel tests avoid the problems of inflating degrees of freedom when data points in distance matrices are not completely independent and allow considerable nonnormality in the dependent variable, they do not allow comparison across compound groups nor the analysis of statistical interaction terms. We therefore also used a multivariate repeated-measures analysis of covariance
(RM-ANCOVA) with chemical (Mahalanobis) distances between each pair of colonies for each of the six compound groups as the (repeated) dependent variables, ant species as a main factor, and genetic distance between fungus clones as a covariate. The dependent variables were ln-transformed to normalize their distribution. This analysis was performed using JMP 5.1 (SAS Institute). Because the unit of replication was the pair of colonies used to calculate the genetic and chemical distances, the approximate significance of each term was assessed using an $F$-test with denominator degrees of freedom reduced based upon the number of colonies being compared (i.e., the total degrees of freedom were limited to 18).

The difference in aggression toward nonnestmates (proportion of ants killed after introduction) before and after exposure to transplanted fungus was tested using a general linear model with binomial errors, evaluating the main effects of ant origin, fungus origin, and treatment (priming with fungus from the receiving colony for 2 weeks) in addition to the 2-way interaction terms between the 3 factors.

\section{Results}

The chemical analyses of fungus profiles revealed a total of 47 compounds in all of the 18 fungus clones examined (see

Table 3 The results of the repeated-measures ANCOVA with compound group as the multivariate dependent variable and ant species and genetic distance between symbionts as main factors

\begin{tabular}{lcccc}
\hline Source & $F$ & $d f$ (reduced $d f)$ & Approximate $P$ value & Canonical correlation \\
\hline Between colony effects: & & & & 0.0003 \\
Ant species & 23.57 & $1,68(1,14)$ & 0.039 & 0.457 \\
Genetic distance & 5.149 & $1,68(1,14)$ & 0.973 & 0.196 \\
Ant species $\times$ genetic distance & 0.0012 & $1,68(1,14)$ & & \\
Within colony effects: & & & & \\
Compound group & 29.28 & $5,64(5,10)$ & 0.0001 \\
Compound group $\times$ ant species & 3.718 & $5,64(5,10)$ & 0.037 \\
Compound group $\times$ genetic distance & 1.114 & $5,64(5,10)$ & 0.412 \\
Compound group $\times$ ant species $\times$ genetic distance & 0.1718 & $5,64(5,10)$ & 0.967 \\
\hline
\end{tabular}

Significance of each term was assessed using $F$-statistics with degrees of freedom reduced based on the number of colonies compared. 
Fig. 2 A midpoint-rooted phylogram of 42 clones of mutualistic fungi cultivated by $A$. echinatior and $A$. octospinosus. One asterisk, two asterisks, and three asterisks indicate bootstrap support above $50 \%, 70 \%$, and $90 \%$, respectively, based on a heuristic parsimony analysis with 1,000 pseudoreplicates under neighbor-joining conditions. The clones used for the comparison of genetic and chemical similarities are marked with black squares

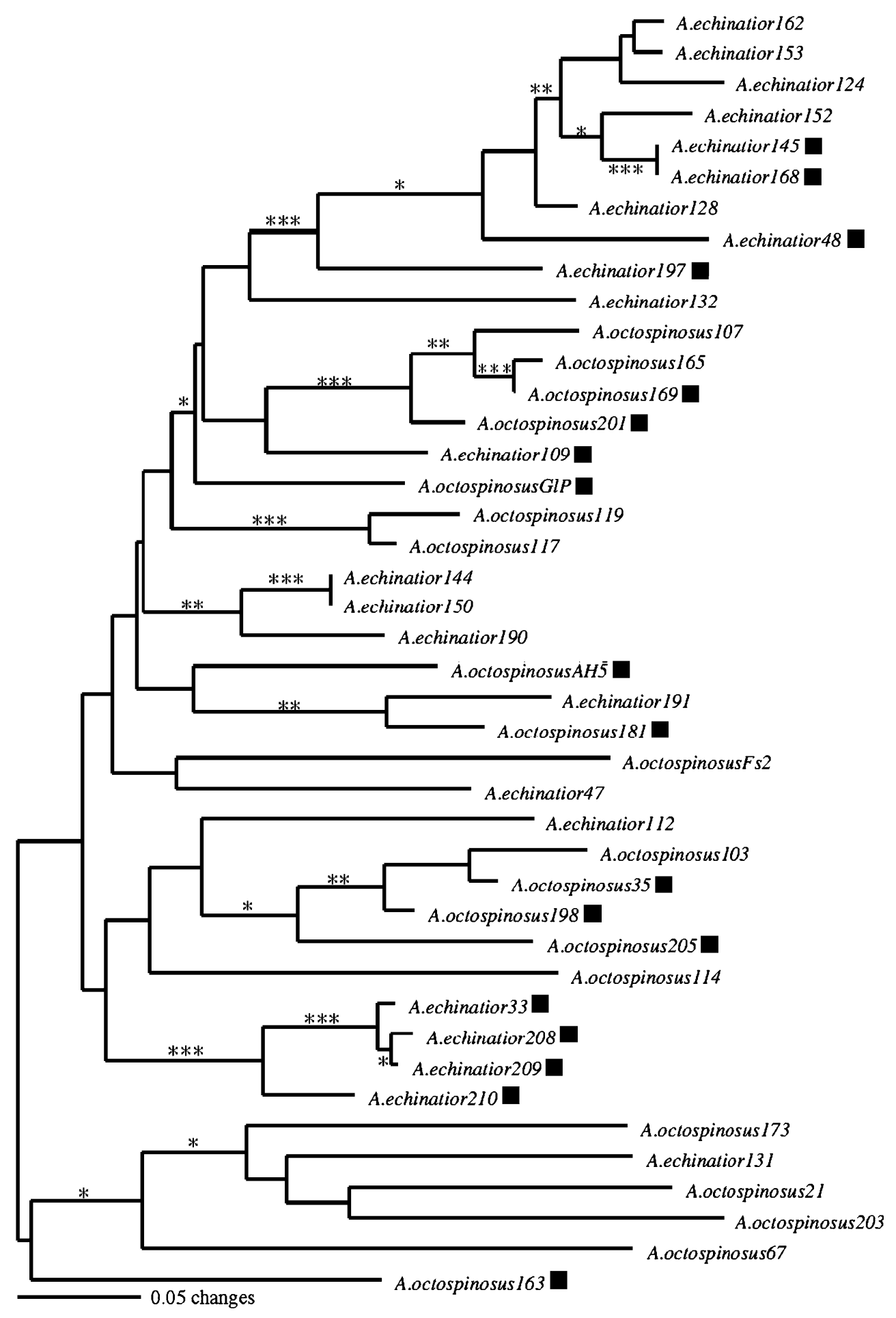

Fig. 1a for a typical example). These were 15 hydrocarbons (13 straight and branched alkanes, plus 2 alkenes), 12 aldehydes, 11 esters ( 5 formates, 3 methyl esters, and 3 acetates), 5 fatty acids, 3 amides, and 1 ketone (Table 1). The first 12 principal components in the analysis based on the covariances of the 37 compounds produced the eigenvalues 0.587 (PC1), 0.452 (PC2), 0.263 (PC3), 0.195 (PC4) 0.155 (PC5), 0.110 (PC6), 0.0788 (PC7), 0.0727
(PC8), 0.0474 (PC9), 0.0434 (PC10), 0.0384 (PC11), and 0.0323 (PC12). The first (PC1), second (PC2), and third (PC3) principal components explained 26.9\%, 20.1\%, and $12.0 \%$ of the variance in peak area, respectively (Fig. 1b), justifying the use of only the first 2 for additional analyses. A nested ANOVA showed that there was a significant difference in $\mathrm{PC} 1$ between fungus gardens raised by the 2 ant species $\left(F_{1,72}=16.38 ; P=0.0009\right)$, which explained 
Fig. 3 The relationship between relative genetic distance and $1 n$ transformed chemical distances for each of the compound groups for A. echinatior (open circles and dashed lines) and $A$. octospinosus (closed circles and solid lines). Least-square regression lines are shown for each plot
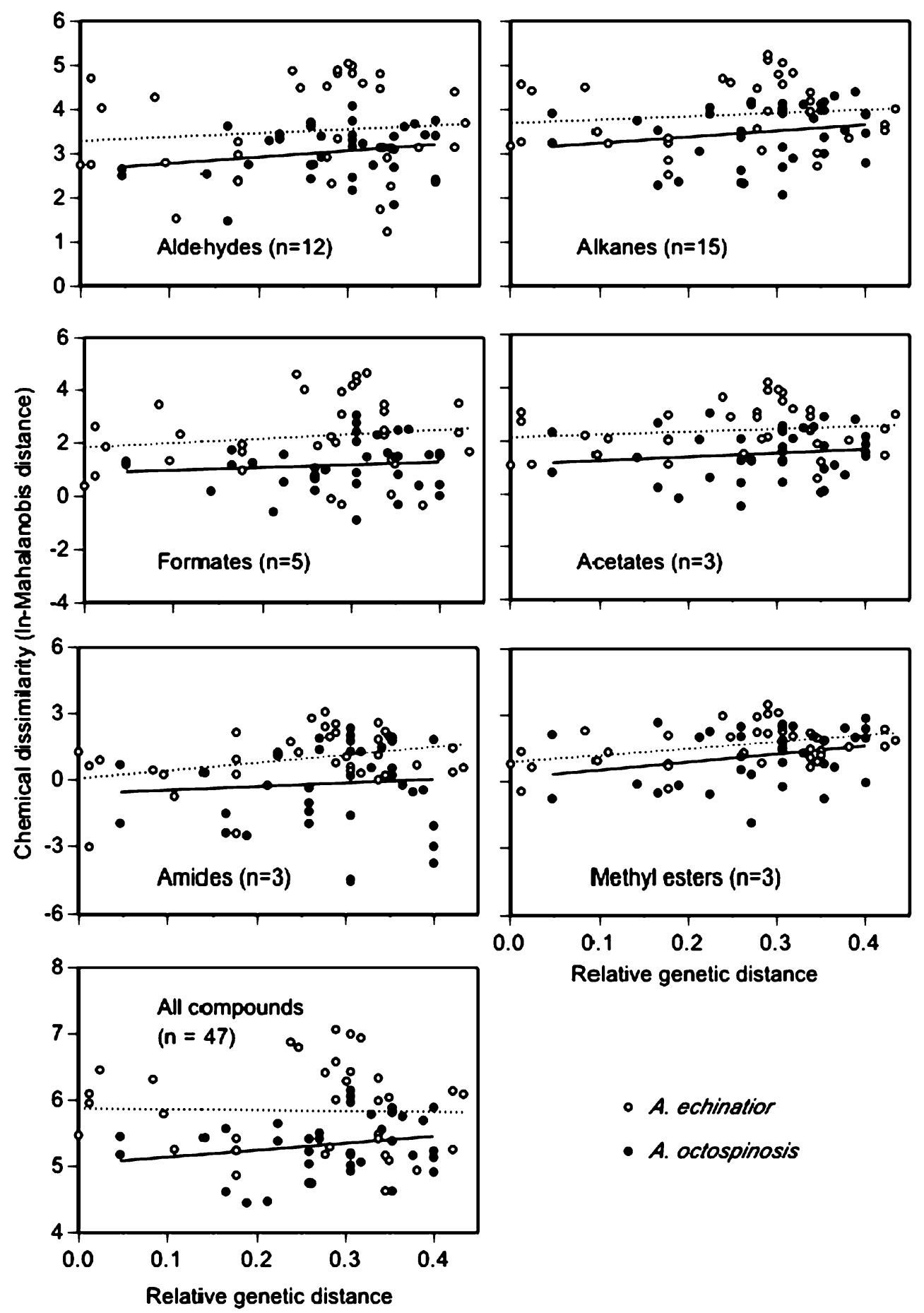

- A. echinatior

- A. octospinosis
$24.1 \%$ of the variance in PC1. There was also a significant effect of colony nested within species on PC1 $\left(F_{16,72}=\right.$ $2.019 ; P=0.0229)$, which explained $23.5 \%$ of the variance in $\mathrm{PC} 1$. For PC2, there was no effect of ant species $\left(F_{1,72}=\right.$ $0.5719 ; P=0.4605,2.49 \%$ of variance in PC2 explained), but a significant difference between colonies nested within species $\left(F_{16,72}=11.30 ; P<0.0001 ; 69.7 \%\right.$ of the variance in PC2 explained) (Fig. 1b).
The phylogenetic analysis of the fungal symbionts was based on 85 characters, of which 75 were parsimonyinformative (polymorphic). This resulted in 1 tree saved with a length of 389, a consistency index (CI) of 0.193 (calculated by dividing the minimum possible number of steps by the observed number of steps), and a retention index (RI) of 0.597 (calculated as the maximum number of steps possible minus the actual number of steps, divided by 
Table 4 The number of nonnestmate workers killed by resident workers when introduced to laboratory colonies before and after 14 days of "priming" exposure to the fungus garden of the receiving test colony $(n=10)$

\begin{tabular}{|c|c|c|c|c|c|c|c|c|c|}
\hline & & \multicolumn{8}{|c|}{ Origin of priming fungus and identity of receiving test colony } \\
\hline & & \multicolumn{2}{|l|}{ Ae 288} & \multicolumn{2}{|c|}{ Ae CC031209-2 } & \multicolumn{2}{|c|}{ Ao CC030403-9 } & \multicolumn{2}{|c|}{ Ao CC031210-22 } \\
\hline & & Before & After & Before & After & Before & After & Before & After \\
\hline \multirow[t]{4}{*}{ Ant origin } & Ae 288 & 0 & 0 & 2 & 1 & 10 & 8 & 9 & 9 \\
\hline & Ae CC031209-2 & 5 & 0 & 1 & 1 & 10 & 2 & 10 & 2 \\
\hline & Ao CC030403-9 & 10 & 3 & 10 & 5 & 1 & 5 & 10 & 6 \\
\hline & Ao CC031210-22 & 10 & 4 & 10 & 4 & 8 & 5 & 0 & 0 \\
\hline
\end{tabular}

The four colonies used were two of A. echinatior (Ae) and two of A. octospinosus (Ao).

the maximum number of steps possible minus the minimum number of steps possible) (Fig. 2). The fungus clones used in this study were, to a large extent, separable with this technique (except for Ae 145 and Ae 168, and Ae 144 and Ae 150, respectively) (Fig. 2). The major groups on the tree are mostly specific to one of the two ant species, but there are also some more mixed groups. This pattern is consistent with the predominant, but not exclusive, vertical transmission of the fungal symbionts (see "Discussion" section).

When considering each compound group in turn, the majority (19 out of 21) of the correlations between genetic distance and Mahalanobis chemical distance between pairs of colonies were positive (Table 2; Fig. 3). Mantel tests showed associations with $P$ values below 0.10 for methyl esters in both of the ant species, for aldehydes in $A$. octospinosus, and for amides in A. echinatior (Table 2; Fig. 3). However, when the two ant species were pooled, there were no apparent associations with genetic distance with the amides as a possible exception (Table 2; Fig. 3). A similar, but clearer pattern was obtained by the RMANCOVA (Table 3), which showed an overall positive and significant correlation between genetic distance and chemical distance across all compound groups independent of the significant effect of ant species. The significant between-compound group differences in ln-Mahalanobis distance are not surprising because there are different numbers of compounds in each group (and the Mahalanobis distance will increase with the number of compounds compared). However, the significant ant species by compound-group interaction term is informative because the same numbers of compounds are involved and implies that there is a difference between the two species in the classes of compound that are under genetic control.

We found no correlations between the geographical distances of the colonies (where they were dug up) and the chemical distance of their fungus gardens, either when considering each of the compound groups separately or when combining them all in a single analysis (Mantel test of the latter: $r=0.036 ; P=0.32$ ). Likewise, there was no correlation between geographic and genetic distance be- tween the fungus gardens across the phylogeny (Ao AH5 from Ancon Hill and Ao FS2 from Fort Sherman were not included; see "Discussion" section) irrespective of whether all colonies were included (Mantel test: $r=0.036 ; P=$ $0.167)$, whether only the subset of colonies where chemical distances known were tested (Mantel test: $r=0.097 ; P=$ 0.138 ) or whether it was a partial test including data on chemistry inserted as an independent matrix to control for the difference in genetic distance between the two groups (Mantel test: $r=0.044 ; P=0.124$ ), confirming previous results inferred from similar relative genetic distance data (Bot et al. 2001) and geographic distances.

Fewer introduced workers were killed by workers in the receiving colonies after the introduced workers had been maintained on fungus material originating from the test colonies for 2 weeks before the experiment $\left(F_{1,9}=13.51, P=\right.$ $0.005)$. The isolated effects of ant origin and fungus origin were not significant $\left(F_{3,9}=1.169, P=0.374\right.$ and $F_{3,9}=1.425$, $P=0.299$, respectively), but there was a significant interaction effect between these two factors $\left(F_{9,9}=6.11, P=0.006\right)$. This indicates that the overall level of mortality depended on the colony combinations, as would be expected when the genetic distances between the four ant colonies involved and/or their fungal symbionts were different. However, neither of the interaction terms involving "treatment" were significant (treatment $\times$ ant origin, $F_{3,9}=0.977, P=0.424$ and treatment $\times$ fungus origin, $F_{3,9}=1.79, P=0.219$, respectively), indicating that the same pattern of reduced mortality was seen with all colonies (Table 4).

\section{Discussion}

When kept under standard laboratory conditions on a substrate of chewed up bramble leaves and rice, the fungi cultivated by $A$. octospinosus and $A$. echinatior express the same chemical compounds, but in different quantities between species and colonies (Fig. 1b; Fig. 2; Table 3). Although there is ample AFLP (whole genome) genetic variation between the fungal symbionts of different colo- 
nies, there is no evidence that the two sympatric Acromyrmex species rear different pools of fungal strains, confirming earlier analyses (Bot et al. 2001; Poulsen and Boomsma 2005). Also, the AFLP tree of Fig. 2 shows some evidence for horizontal transmission between the two ant species, but to a lesser extent that a previous AFLP tree on Acromyrmex fungal symbionts from the same area (Bot et al. 2001). The quantitative variation in symbiont-produced chemical profiles appears to be heritable to some extent, and priming of nonnestmate workers with alien symbiont appears to affect nestmate recognition from the workers maintaining this fungus as their resident symbiont (Table 4). In the sections below, we will discuss and interpret these complex patterns and evaluate the possible significance of fungal-derived cues for nestmate recognition.

Discriminating between ant-derived and fungus-derived recognition cues

The fungi cultivated by Acromyrmex ants can acquire their chemical compounds from the environment (the worker or queen ants, the ant brood, the collected leaf fragments) (Viana et al. 2001; Richard et al. 2004) and/or produce them independently. In this study, the variation in the environmental component was inevitably low because ants were reared under the same controlled laboratory conditions and on a standard diet of mostly bramble leaves, which only contain aliphatic $\mathrm{C} 14-\mathrm{C} 26$ aldehydes and a few $n$-alkanes and $n$-alkenes (Richard et al. 2004). Our constant laboratory-feeding regime has therefore almost certainly reduced the natural environmental variation in chemical profiles. In a related Brazilian ant, Acromyrmex subterraneus, the compounds found in fungus material included all the hydrocarbons present on the surface of larvae and pupae of the tending ants, but also in that study, the fungus expressed many additional compounds (Viana et al. 2001). Although the authors did not state this, the data clearly suggest that the fungus produces several classes of compounds that the ants do not synthesize. A recent study of A. echinatior workers from the same Panamanian population has confirmed this hypothesis by showing that ant workers had only alkanes, alkenes, and methyl alkanes on their cuticles (Lambardi et al. 2007). This indicates that the aldehydes, methyl esters, and amides, which appear to covary with genetic differences between fungal symbionts (Table 2; Fig. 3), are indeed innate fungal compounds.

Of the 31 compounds isolated from the Brazilian fungus gardens of A. subterraneus (Viana et al. 2001), 16 were identical to compounds isolated from the fungus clones of our 2 Panamanian Acromyrmex species, which suggests that chemical profiles of fungal symbionts may be similar across the entire genus of Acromyrmex leaf-cutting ants. The chemical similarity between Panamanian and Brazilian symbionts of Acromyrmex might be even higher because we potentially could have obtained the C-35 alkane and the unidentified aldehyde present in A. subterraneus fungus garden profiles (Viana et al. 2001) with a different gas chromatography-mass spectrometry (GC-MS) analysis. Other differences may have been due to the Brazilian ants being provided with different forage (Ligustrum leaves). Finally, the multiple branched alkanes found in symbiont fungi by Viana et al. (2001) might have originated from the chemical profile of workers and brood where they were present in low quantities (Richard et al. 2004; F.-J. Richard, unpublished data) and thus do not necessarily contradict our present finding of only a single branched alkane (8methyloctadecane) in fungus material without brood.

Several independent findings indicate that the mutualistic fungus maintained by Acromyrmex leaf-cutting ants displays a substantially richer blend of chemical compounds than their host ants and the ant brood. The expressed quantities of the apparently fungal-derived compounds (aldehydes, methyl esters, and amides) appear heritable to some extent, and may thus function as recognition labels for the ants to discriminate between strains of fungi. The current data do not allow us to assess whether the alkanes, expressed by both the ants and their fungi, are primarily ant-derived or fungus-derived. The most parsimonious hypothesis would be that the compounds expressed on the ant cuticle are ultimately determined by what the ants eat (i.e., by the total chemical blend of their fungal food), but proximately by ant speciesspecific biosynthetic pathways, so that only alkanes, alkenes, and methyl alkanes are expressed (Lambardi et al. 2007). If so, these simple hydrocarbons would likely be transferred back to the fungus garden, which would explain why their relative quantities do not correlate with the genetic differences among the strains of symbionts. This hypothesis, which we will explore in more detail below, would imply that fungal symbionts have an important indirect effect on the expression and maintenance of a colony "gestalt" odor in leaf-cutting ants.

\section{The logic of symbiont-derived recognition cues}

While it is clearly important for leaf-cutting ants to recognize their colony's own symbiotic fungus and to discriminate against alien fungi (Poulsen and Boomsma 2005), there are also several reasons why fungal-derived recognition profiles might be more reliable for nestmate recognition than ant-derived cuticular hydrocarbon profiles. Because queens mate with many males (Ortius-Lechner et al. 2003; Sumner et al. 2004), the workers in individual colonies are much more genetically variable than the fungus they rear. The genetic make-up of the ants tending a fungal lineage also changes significantly in each generation because 
representatives of the female lineage (transmitting the symbiont) mate at random with different sets of males. There is, therefore, no direct connection across generations between the largely vertically transmitted fungal symbiont and the nuclear genetic variation of the ants. This implies that fungus-derived recognition cues would be more distinct and better preserved between ant generations than antderived cues because default vertical transmission remains much more common on an ecological timescale than occasional horizontal transmission events, the signs of which can often be detected only in comparisons of fungal symbionts across sympatric ant species (e.g., Fig. 2 and Bot et al. 2001).

Using symbiont-derived recognition cues would allow workers to discriminate between nestmates and nonnestmates provided that neighboring colonies rear genetically different strains of fungus. This is likely to be the case because only 2 out of the 42 pairs of fungus clones examined in this study had identical AFLP profiles (Fig. 2). Any additional habitat-specific environmental factors would then simply reinforce a fungus-induced "gestalt", in concordance with the finding of Jutsum et al. (1979) that ant forage is a key factor in intraspecific recognition between $A$. octospinosus workers. These difference-enhancing environmental effects are likely to be primarily local (i.e., nest-level and feeding-territory specific), which is consistent with the lack of correlation between the geographic distance between colonies and the chemical or genetic distance of their fungal symbionts within the Gamboa population covering an area of approximately $1 \mathrm{~km}^{2}$. This is further supported by the chemical profiles from 2 colonies (Ao AH5 and Ao FS2), which were excavated 25 and $35 \mathrm{~km}$ from Gamboa, respectively, but had chemical (Fig. 1b) and AFLP (Fig. 2) profiles similar to those from Gamboa colonies. Thus, although these distant colonies were not included in the analysis of geographic vs genetic and chemical differences, they most likely were representatives in the same population of fungal symbionts.

\section{Exploring some of the consequences of symbiont- derived recognition cues}

Nestmate recognition and aggressive behavior between Acromyrmex ants are normally distinct in encounters between individuals originating from the same colony after being raised in subcolonies provided with different forage (Jutsum et al. 1979) or when confrontations are staged on or close to the fungus garden of colonies (Lambardi et al. 2007; Table 4). However, in other cases, aggression between workers from different laboratory colonies raised on the same food is surprisingly mild, particularly during encounters away from the fungus garden (F.-J. Richard, unpublished data; J.J. Boomsma, personal observation). This might indicate that either (1) Acromyrmex workers sometimes do not have many nestmate recognition cues available after having been kept on the same constant laboratory diet for a long time or (2) aggression toward nonnestmates is lower when encounters occur away from the valuable colony fungus garden, i.e., in the foraging territory rather than in the nest sphere. These reduced aggression levels owing to information constraints or lower "motivation" are less likely to be important for the recognition of fungus fragments by the ants because (1) fungal profiles appear to retain much of their distinctness even after a long time in laboratory culture on the same leaf substrate (Fig. 1), facilitating correct recognition within gardens, and (2) recognition of nonresident fungus material away from the resident garden may also be important to avoid accidentally bringing back contaminant fungus material with potentially severe consequences (cf. Poulsen and Boomsma 2005).

It is striking that most of the correlations of Table 2 and Fig. 3 disappeared when we pooled the data from both ant species, in spite of the substantial increase in sample size. This suggests that active care by ants may have different species-specific effects on the production of classes of fungal compounds, or possibly on the expression of genes that control the metabolism, and hence the surface chemistry of the fungal symbiont. The interaction complexity between genetic, environmental, and host factors that apparently determines the chemical profile of the fungal symbionts may also explain why the correlations (Fig. 3) are generally weak. The unusually deviating chemical signature of the symbiont of colony Ae 33 in Fig. 1b may provide a suggestive illustration as this was the only $A$. echinatior colony that was sampled in typical $A$. octospinosus (forest) habitat. The symbiont of this colony belonged to a typical $A$. echinatior clade of symbionts (Fig. 2) normally found in less shaded habitats, but its unusual habitat to which its tending ants were not specifically adapted, might have affected gene expression for key metabolic pathways in peculiar ways with a deviating chemical profile as a result.

Several studies have focused on the sensitive imprinting period after worker emergence and have shown that early learning of the colony odor by callow workers determines later nestmate discrimination (e.g., Hölldobler and Wilson 1990; Fénéron and Jaisson 1995). This imprinting process on a specific "gestalt" odor should be equally as effective with fungus-derived compounds as with innate cuticular hydrocarbons. The hypothesis that many recognition cues in leafcutting ants are ultimately fungus-derived yields the prediction that the perception of "own fungus" can be manipulated in symbiont exchange experiments, similar to what can be done with innate cuticular hydrocarbon profiles when rearing ants 
from the same colony on different food sources (Jutsum et al. 1979). We therefore expected to also be able to manipulate aggressive behavior of ants toward nonnestmates after experimentally priming and acclimatizing them to nonresident fungus material, and we were able to show this in a direct experiment (Table 4).

Our results mean that we now have multiple lines of evidence suggesting that the interactions between leafcutting ants and their fungal symbionts are a complex blend of cooperation and potential conflict, extending into which chemical cues are expressed and used by each of the parties: These are (1) the fact that a period of 1-2 weeks without the resident fungus, or with enforced exposure to and feeding on a previously incompatible symbiont, removes or reverses behavioral ant-fungus incompatibility (Bot et al. 2001; F.-J. Richard, personal observation), (2) the evidence that resident fungus clones actively protect their local monopoly of ant care by expressing genetically determined mycelial incompatibility toward alien strains of symbiont and by imprinting the fecal droplets of the ants to express the same incompatibility (Poulsen and Boomsma 2005), (3) that the fungi have partly heritable chemical profiles independent of the ants and that these chemical profiles affect aggression level toward nonnestmates and thus the colony gestalt odor. Further unraveling of these complex interactions will be highly rewarding to understand the principles of communication and recognition involved in host symbiont coevolution.

Acknowledgements We thank A.N.M. Bot, S. Rønhede, and S.M. Mathiasen for the assistance with fungus culturing and obtaining the AFLP data; J.S. Pedersen and G. Nachman for statistical advice; C.R. Currie for providing some of the experimental lab colonies; $P$. D'Ettorre for comments on the manuscript; the Smithsonian Tropical Research Institute (STRI) for providing logistic help and facilities to work in Gamboa; and the Autoridad Nacional del Ambiente y el Mar (ANAM) for the permission to sample ant colonies in Panama and export them to Denmark. Fieldwork was supported by grants from the Carlsberg foundation and the Danish Natural Science Research Council to JJB. All experiments performed in this manuscript comply with current Danish and USA laws.

\section{References}

Aitchison J (2003) The statistical analysis of compositional data, 2nd edn. Blackburn, Caldwell, New Jersey

Bass M, Cherrett JM (1994) The role of leaf-cutting ant workers (Hymenoptera: Formicidae) in the fungus garden maintenance. Ecol Entomol 19:215-220

Belt T (1874) The naturalist in Nicaragua. University of Chicago Press, Chicago

Bot ANM, Rehner SA, Boomsma JJ (2001) Partial incompatibility between ants and symbiotic fungi in two sympatric species of Acromyrmex leaf-cutting ants. Evolution 55:1980-1991
Bot ANM, Orthius-Lechner D, Finster K, Maile R, Boomsma JJ (2002) Variable sensitivity of fungi and bacteria to compounds produced by the metapleural glands of leaf-cutting ants. Insectes Soc 49:363-370

Breed MD (1998) Chemical cues in kin recognition: criteria for identification, experimental approaches, and the honey bee as an example. In: Vander Meer RK, Breed MD, Espelie KE, Winston ML (eds) Chemical communication in social insects. Westview, Boulder, Colorado, pp 57-78

Chapela IH, Rehner SA, Schultz TR, Mueller UG (1994) Evolutionary history of the symbiosis between fungus-growing ants and their fungi. Science 266:1691-1694

Cherrett JM, Powell RJ, Stradling DJ (1989) The mutualism between leaf-cutting ants and their fungi. In: Wilding N, Collins NM, Hammond PM, Webber JF (eds) Insect-fungus interactions. Academic, London, pp 93-116

Crozier RH, Dix MW (1979) Analysis of two genetic models for the innate components of colony odour in social Hymenoptera. Behav Ecol Sociobiol 4:217-224

Currie CR, Stuart AE (2001) Weeding and grooming of pathogens in agriculture by ants. Proc R Soc Lond B 268:1033-1039

Currie CR, Scott JA, Summerbell RC, Malloch D (1999) Fungusgrowing ants use antibiotic bacteria to control garden parasites. Nature 398:701-704

Currie CR, Scott JA, Summerbell RC, Malloch D (2003) Corrigendum: Fungus-growing ants use antibiotic-producing bacteria to control garden parasites. Nature 423:461

Currie CR, Poulsen M, Mendenhall J, Boomsma JJ, Billen J (2006) Coevolved crypts and exocrine glands support mutualistic bacteria in fungus-growing ants. Science $311: 81-83$

Fénéron R, Jaisson P (1995) Ontogeny of nestmate brood recognition in a primitive ant, Ectatomma tubercalutum Olivier (Ponerinae). Anim Behav 50:9-14

Fletcher DJC, Michener CD (1987) Kin recognition in animals. Wiley, New York

Goudet J (1995) FSTAT (version 1.2): a computer program to calculate $F$-statistics. J Heredity 86:485-486, http://www.unil. $\mathrm{ch} /$ izea/softwares/fstat.html

Hall BG (2001) Phylogenetic analysis made easy: a how-to-do manual for molecular biologists. Sinauer Associates, Sunderland, Massachusetts

Heinze J, Foitzik S, Hippert A, Hölldobler B (1996) Apparent dearenemy phenomenon and environment-based recognition cues in the ant Leptothorax nylanderi. Ethology 102:510-522

Hölldobler B, Wilson EO (1990) The ants. Harvard University Press, Cambridge

Jutsum AR, Saunders TS, Cherrett JM (1979) Intraspecific aggression in the leaf-cutting ant Acromyrmex octospinosus. Anim Behav 27:839-844

Lambardi D, Dani FR, Turillazzi S, Boomsma JJ (2007) Chemical mimicry in an incipient leaf-cutting ant social parasite. Behav Ecol Sociobiol 61:843-851, DOI 10.1007/s00265-006-0313-y

Lenoir A, Fresneau D, Errard C, Hefetz A (1999) Individuality and colonial identity in ants: the emergence of the social representation concept. In: Destrain C, Deneubourg JL, Pasteels JM (eds) Information processing in social insects. Birkhäuser, Berlin, pp 219-237

Littledyke M, Cherrett JM (1976) Direct ingestion of plant sap from cut leaves by the leaf-cutting ants Atta cephalotes (L.) and Acromyrmex octospinosus (Reich) (Formicidae, Attini). Bull Entomol Res 66:205-217

Mantel N (1967) The detection of disease clustering and a generalized regression approach. Cancer Res 27:209-220

Mehdiabadi NJ, Hughes B, Mueller UG (2006) Cooperation, conflict, and coevolution in the attine ant-fungus symbiosis. Behav Ecol $17: 291-296$ 
Möller A (1893) Die pilzgarten einiger südamerikanischer ameisen. Gustav Fisher, Jena

Mueller UG, Poulin J, Adams RMM (2004) Symbiont choice in a fungus-growing ant (Attini, Formicidae). Behav Ecol 15:357-364

Murakami T, Higashi S (1997) Social organization in two primitive attine ants, Cyphomyrmex rimosus and Myrmicocrypta ednaella, with reference to their fungus substrates and food sources. J Ethol $15: 17-25$

Nielsen J, Boomsma JJ, Oldham NJ, Petersen HC, Morgan ED (1999) Colony-level and season-specific variation in cuticular hydrocarbon profiles of individual workers in the ant Formica truncorum. Insectes Soc 46:58-65

North RD, Jackson CW, Howse PE (1997) Evolutionary aspects of ant-fungus interactions in leaf-cutting ants. Trends Ecol Evol 12:386-389

Ortius-Lechner D, Maile R, Morgan ED, Petersen HC, Boomsma JJ (2003) Lack of patriline-specific differences in chemical composition of the metapleural gland secretion in Acromyrmex octospinosus. Insectes Soc 50:113-119

Poulsen M, Boomsma JJ (2005) Mutualistic fungi control crop diversity in fungus-growing ants. Science 307:741-744

Quinlan RJ, Cherrett JM (1979) The role of fungus in the diet of the leaf-cutting ant Atta cephalotes (L.). Ecol Entomol 4:151-160

Richard FJ, Hefetz A, Christides JP, Errard C (2004) Food influence on colonial recognition and chemical signature between nestmates in the fungus-growing ant Acromyrmex subterraneus subterraneus. Chemoecology 14:9-16

Schneider M (2000) Observations on brood care behaviour of the leafcutting ant Atta sexdens L. (Hymenoptera: Formicidae). In: Abstracts of the XXI International Congress of Entomology, vol. 2 (August 20-26, 2000, Foz do Iguassu). Embraja Sojo, London, p 895

Schneider S, Roessli D, Excoffier L (2000) ARLEQUIN, ver. 2.000: software for population genetics data analysis. Genetics and Biometry Laboratory, University of Geneva, Switzerland, http://www.anthro.unige.ch/arlequin

Silverman J, Liang D (2001) Colony disassociation following diet partitioning in a unicolonial ant. Naturwissenschaften 88:73-77

Singer TL (1998) Roles of hydrocarbons in the recognition systems of insects. Am Zool 38:394-405

Soroker V, Vienne C, Hefetz A, Nowbahari E (1994) The postpharyngeal gland as a "Gestalt" organ for nestmate recognition in the ant Cataglyphis niger. Naturwissenschaften 81:510-513

Sumner S, Hughes WOH, Pedersen JS, Boomsma JJ (2004) Ant parasite queens revert to mating singly. Nature 428:35-36

Swofford DL (2002) PAUP*: phylogenetic analysis using parsimony (*and other methods), version 4.0b10. Sinauer Associates. Sunderland, Massachusetts

Vander Meer RK, Morel L (1998) Nestmate recognition in ants. In: Vander Meer RK, Breed M, Winston M, Espelie KE, Winston ML (eds) Pheromone communication in social insects. Westview, Boulder, Colorado, pp 79-103

Viana AMM, Frézard A, Malosse C, Della Lucia TMC, Errard C, Lenoir A (2001) Colonial recognition of fungus in the fungus growing ant Acromyrmex subterraneus subterraneus (Hymenoptera: Formicidae). Chemoecology 11:29-36

Vos P, Hogers R, Bleeker M, Reijans M, van de Lee T et al (1995) AFLP: a new technique for DNA fingerprinting. Nucleic Acid Res 23:4407-4414

Weber NA (1966) Fungus-growing ants. Science 153:587-604 